\title{
Socioeconomic and demographic predictors of mortality and institutional residence among middle aged and older people: results from the Longitudinal Study
}

\author{
Elizabeth Breeze, Andy Sloggett, Astrid Fletcher
}

\begin{abstract}
Study objectives-To identify socioeconomic and demographic predictors of long term mortality and institutional residence in old age, taking into account changes in socioeconomic and demographic circumstances between the 1971 and 1981 censuses.

Design-Multivariate logistic regression modelling of outcomes for 10 year age cohorts of each gender. The outcomes were death by 31 December 1992; being in an institution in 1991.

Setting-Members of the Longitudinal Study (a 1\% sample of the British Census): 43092 men and 50839 women aged 55-74 in 1971.

Main results-Being in rented accommodation and in a household without access to a car carried $35-45 \%$ higher mortality rate over 21 years and similar excess risk of being in an institution in 1991. Marital status and living arrangements were weaker predictors of death but being single was a major predictor of moving to an institution for men. Losing household access to a car was a strong factor for mortality for men and for institutionalisation for men aged 55-64 in 1971. The effects were weaker for women. Moving into rented accommodation was a predictor of both outcomes for women and of death for the younger cohort of men. People who started to live alone in the inter-census period were at reduced risk of dying.

Conclusions-These results demonstrate persistence of inequalities in health related outcomes throughout old age, both in those with unfavourable circumstances in mid-life and in those who, in later life, have lost earlier advantages

(F Epidemiol Community Health 1999;53:765-774)
\end{abstract}

Department of Epidemiology and Population Health, London School of Hygiene and Tropical Medicine, Keppel Street, London WC1E 7HT

Correspondence to: E Breeze.

Accepted for publication 25 April 1999

health has focused mainly on mortality the age of 65 years. Less attention has been paid to older age groups, in part because of difficulties in assigning socioeconomic status to retired people, and perhaps because of assumptions that the aging process is the main determinant of health outcomes. Prospective data linking social class (based on current or previous occupation recorded at the 1971 census) and mortality up to 10 years, showed the steep class gradient persisting into old age. The results for women were not reported. ${ }^{1}$ Other descriptors of socioeconomic status, such as housing tenure, car ownership, are less prone to gender and age bias and have been shown to predict mortality in elderly people in shortterm follow up (10 years). ${ }^{2}$

A minority of people end their days in a communal establishment such as a residential or nursing home. Over the past decade institutional care for elderly people in the United Kingdom rose by around 30\%, reflecting both the increasing numbers in this age group in the population ${ }^{3}$ and increasing proportions entering institutions. ${ }^{4}$ Little is known of the long term risk of institutional care in old age for people in middle age and early retirement.

In this study we examined the association between socioeconomic and demographic factors and mortality over a period of 21 years, and looked at the relations between changes in these circumstances in the first 10 years and both subsequent mortality and institutional residence at the end of the period. Although mortality relative to changes in social class ${ }^{5} 6$ and housing tenure ${ }^{7}$ at working ages have been reported and changes in household circumstances among the elderly ${ }^{8}$ have been described, the effects of those changes on mortality and institutional residence among older people in Great Britain had not been looked at previously.

\section{Methods}

DATA SOURCE

The Longitudinal Study (LS) links data from successive censuses since 1971 with routinely collected vital registration data from the National Health Service Central Register (NHSCR). ${ }^{9} \quad$ At any one time the study represents a one per cent sample of the England and Wales population. Mortality data were taken from the NHSCR and other data from the 1971 and 1981 censuses. Of the original 1971 members of all ages $97 \%$ were identified on the NHSCR and $92 \%$ at the 1981 census. ${ }^{9}$ 
alive in April 1971 including those in institutions and (2) for deaths after April 1981 for people living in the community in both 1971 and 1981. A third approach explored intercensus changes in socioeconomic and demographic factors as potential predictors of mortality. For institutional residence we looked at risks of being in an institution in 1991 among those who were alive in 1991 and lived in the community in both 1971 and 1981, comparing risks both by circumstances in 1971 and by inter-census changes in those circumstances. An institution, as defined by the census, is any establishment where people have some form of communal catering. From 1981 it excludes sheltered housing if more than half the people living in the complex possess facilities for cooking their own meals. ${ }^{11}{ }^{11}$ In 1971 there were no guidelines about sheltered housing and it is not clear how people were classified.

The socioeconomic risk factors available on the census reflect material circumstances (housing tenure and car availability for the household) and occupation-based social class; the other factors we included may indicate the presence of psychological and practical support (de facto marital status and whether living alone). The housing tenure and car availability categories refer to the household; the subject does not have to be the owner to be classified as in owneroccupied accommodation, nor to be a car owner or car user to be in the category of household with a car. The subject's individual and household status will most often differ when the subject is living with someone other than their spouse. Currently married women are assigned their husband's social class, others their own social class. This assumes that social class is a family characteristic rather than a personal one.

The hypotheses investigated were: (1) poorer socioeconomic circumstances and (2) being in a situation without the support of spouse or a co-resident are associated with greater risks of mortality; (3) deterioration in socioeconomic and living circumstances in middle age or early old age is associated with mortality risks of similar magnitude to those who already had less favourable circumstances at baseline - that is, that changes in life circumstances have an impact in later life; (4-6) similar hypotheses for risks of being in an institution at the 1991 census.

\section{STATISTICAL ANALYSIS}

Multivariate logistic regression ${ }^{12}$ was used to assess association between potential predictors and risk of mortality up to the end of 1992, the last year for which mortality data were available. Odds ratios approximate risk ratios when the risk is small, as in moving into an institution; for mortality where the outcome is common the risk ratios were derived from logit models. Mortality risks were adjusted for five year time bands in the models by 1971 characteristics and for three year periods in the models by inter-census changes. By including time bands we allowed for absolute risk levels to vary over time while assuming that risk ratios remained constant. Tables 2, 4, 6 and 7 show (1) risk ratios adjusted only for five year age bands (and time where appropriate) and (2) the risk ratios fully adjusted for all factors. Unless otherwise specified the ratios quoted in the text refer to those for models that are adjusted for all the factors.

Analyses were also undertaken comparing relative risk of death in the first years with relative risks in the later years in case selection of those in poor health into certain socioeconomic and demographic groups accounted for variation in mortality risk between them. If people belong to a certain category as a result of ill health, especially acute illness, the death rate for that group will be higher than that of

Table 1 Baseline characteristics of $(A)$ all men and women in the 1971 LS sample, $(B)$ those in the community in 1971 and 1981 and alive in 1991

\begin{tabular}{|c|c|c|c|c|c|c|c|c|}
\hline \multirow[b]{2}{*}{ Characteristic in April 1971} & \multicolumn{4}{|l|}{ Men } & \multicolumn{4}{|l|}{ Women } \\
\hline & Age 55-64 & & $65-74$ & & Age 55-64 & & $65-75$ & \\
\hline & A & B & A & B & A & B & A & B \\
\hline Marital status/whether alone & $\%$ & $\%$ & $\%$ & $\%$ & $\%$ & $\%$ & $\%$ & $\%$ \\
\hline Married/cohabiting & 87 & 89 & 81 & 87 & 70 & 72 & 48 & 54 \\
\hline \multicolumn{9}{|l|}{ Single } \\
\hline alone & 3 & 2 & 2 & 2 & 4 & 4 & 6 & 6 \\
\hline not alone & 4 & 3 & 3 & 2 & 5 & 4 & 6 & 5 \\
\hline \multicolumn{9}{|l|}{ Widowed } \\
\hline alone & 2 & 2 & 7 & 5 & 9 & 8 & 24 & 22 \\
\hline not alone & 2 & 1 & 5 & 3 & 8 & 7 & 12 & 9 \\
\hline \multicolumn{9}{|l|}{ Divorced/separated } \\
\hline alone & 1 & 1 & 1 & 1 & 2 & 2 & 2 & 2 \\
\hline not alone & 2 & 2 & 1 & 1 & 2 & 3 & 1 & 2 \\
\hline Housing tenure and car availability & $\%$ & $\%$ & $\%$ & $\%$ & $\%$ & $\%$ & $\%$ & $\%$ \\
\hline In owner-occupation, car & 36 & 45 & 27 & 38 & 31 & 35 & 20 & 25 \\
\hline In owner-occupation, no car & 15 & 13 & 25 & 24 & 20 & 20 & 30 & 31 \\
\hline In rented accommodation, car & 20 & 21 & 10 & 12 & 15 & 16 & 7 & 7 \\
\hline In rented accommodation, no car & 27 & 21 & 36 & 26 & 32 & 29 & 41 & 37 \\
\hline In institution & 1 & - & 2 & - & 1 & - & 2 & - \\
\hline Social class* & $\%$ & $\%$ & $\%$ & $\%$ & $\%$ & $\%$ & $\%$ & $\%$ \\
\hline I/II & 22 & 27 & 18 & 24 & 18 & 20 & 13 & 17 \\
\hline IIIN & 11 & 11 & 11 & 15 & 13 & 14 & 9 & 11 \\
\hline IIIM & 33 & 34 & 27 & 27 & 24 & 25 & 14 & 16 \\
\hline IV/V & 29 & 25 & 31 & 28 & 26 & 25 & 19 & 20 \\
\hline Unclassified + & 6 & 2 & 12 & 6 & 19 & 16 & 44 & 36 \\
\hline Number & 26222 & 8947 & 16870 & 1517 & 28383 & 15458 & 22895 & 4604 \\
\hline
\end{tabular}

*Social class derived from occupation at the census or most recent occupation. Currently married women have been assigned the social class of their husband, other women their own social class. †Those who could not be assigned a class either because of inadequate information or because they did not have an occupation. 
Table 2 Risk ratio (RR), 95\% confidence intervals (CI) and p values for mortality 1971-1992 by baseline demographic and socioeconomic circumstances by age

\begin{tabular}{|c|c|c|c|c|c|c|c|c|}
\hline \multirow[b]{2}{*}{ Characteristic in 1971} & \multicolumn{4}{|c|}{ 55-64 years in 1971} & \multicolumn{4}{|c|}{$65-74$ years in 1971} \\
\hline & $R R^{\star}$ & $\begin{array}{l}\text { Adjt } \\
R R\end{array}$ & $95 \% C I$ & $p$ value & $R R^{*}$ & $\begin{array}{l}\text { Adjt } \\
R R\end{array}$ & $95 \% C I$ & $p$ value \\
\hline \multicolumn{9}{|l|}{ Men } \\
\hline \multicolumn{9}{|l|}{ Marital status/whether alone } \\
\hline Married/cohabiting & 1.00 & 1.00 & & & 1.00 & 1.00 & & \\
\hline \multicolumn{9}{|l|}{ Single } \\
\hline alone & 1.26 & 1.12 & $1.01,1.24$ & 0.03 & 1.17 & 1.11 & $0.99,1.23$ & 0.07 \\
\hline not alone & 1.34 & 1.14 & $1.04,1.25$ & 0.00 & 1.33 & 1.21 & $1.09,1.34$ & 0.00 \\
\hline \multicolumn{9}{|l|}{ Widowed } \\
\hline alone & 1.17 & 1.07 & $0.96,1.20$ & 0.21 & 1.10 & 1.06 & $0.99,1.14$ & 0.08 \\
\hline not alone & 1.29 & 1.24 & $1.11,1.38$ & 0.00 & 1.26 & 1.26 & $1.16,1.36$ & 0.00 \\
\hline \multicolumn{9}{|l|}{ Divorced/separated } \\
\hline alone & 1.26 & 1.16 & $1.02,1.32$ & 0.02 & 1.20 & 1.15 & $0.98,1.33$ & 0.08 \\
\hline not alone & 1.31 & 1.19 & $1.04,1.35$ & 0.01 & 1.51 & 1.36 & $1.15,1.59$ & 0.00 \\
\hline \multicolumn{9}{|l|}{ Social class } \\
\hline $\mathrm{I} / \mathrm{II}$ & 1.00 & 1.00 & & & 1.00 & 1.00 & & \\
\hline IIIN & 1.17 & 1.10 & $1.03,1.17$ & 0.00 & 1.05 & 0.98 & $0.92,1.05$ & 0.71 \\
\hline IIIM & 1.24 & 1.12 & $1.07,1.17$ & 0.00 & 1.23 & 1.11 & $1.05,1.17$ & 0.00 \\
\hline IV/V & 1.42 & 1.20 & $1.15,1.26$ & 0.00 & 1.24 & 1.08 & $1.02,1.14$ & 0.01 \\
\hline Unclassified & 2.57 & 2.21 & $2.07,2.36$ & 0.00 & 1.41 & 1.24 & $1.16,1.32$ & 0.00 \\
\hline \multicolumn{9}{|l|}{ Tenure and car availability } \\
\hline Owner occupation, with car & 1.00 & 1.00 & & & 1.00 & 1.00 & & \\
\hline Owner occupation, no car & 1.34 & 1.26 & $1.19,1.32$ & 0.00 & 1.21 & 1.19 & $1.13,1.24$ & 0.00 \\
\hline Renting, with car & 1.25 & 1.21 & $1.16,1.27$ & 0.00 & 1.15 & 1.12 & $1.05,1.19$ & 0.00 \\
\hline Renting, no car & 1.59 & 1.44 & $1.38,1.50$ & 0.00 & 1.41 & 1.36 & $1.31,1.42$ & 0.00 \\
\hline Communal & 1.97 & 1.25 & $1.07,1.47$ & 0.01 & 1.99 & 1.59 & $1.37,1.81$ & 0.00 \\
\hline \multicolumn{9}{|l|}{ Women } \\
\hline \multicolumn{9}{|l|}{ Marital status/whether alone } \\
\hline Married/cohabiting & 1.00 & 1.00 & & & 1.00 & 1.00 & & \\
\hline \multicolumn{9}{|l|}{ Single } \\
\hline alone & 1.09 & 1.02 & $0.94,1.12$ & 0.61 & 1.02 & 0.96 & $0.90,1.04$ & 0.32 \\
\hline not alone & 1.10 & 0.98 & $0.90,1.07$ & 0.72 & 1.09 & 0.96 & $0.88,1.03$ & 0.24 \\
\hline \multicolumn{9}{|l|}{ Widowed } \\
\hline alone & 1.18 & 0.99 & $0.92,1.05$ & 0.71 & 1.06 & 0.93 & $0.88,0.98$ & 0.01 \\
\hline not alone & 1.20 & 1.05 & $0.98,1.12$ & 0.20 & 1.29 & 1.19 & $1.13,1.26$ & 0.00 \\
\hline \multicolumn{9}{|l|}{ Divorced/separated } \\
\hline alone & 1.19 & 0.94 & $0.82,1.08$ & 0.40 & 1.08 & 0.93 & $0.81,1.07$ & 0.32 \\
\hline not alone & 1.27 & 0.96 & $0.84,1.10$ & 0.59 & 1.24 & 0.99 & $0.85,1.14$ & 0.85 \\
\hline \multicolumn{9}{|l|}{ Social class of self/spouse } \\
\hline $\mathrm{I} / \mathrm{II}$ & 1.00 & 1.00 & & & 1.00 & 1.00 & & \\
\hline IIIN & 1.02 & 0.96 & $0.90,1.03$ & 0.27 & 1.04 & 0.99 & $0.92,1.06$ & 0.78 \\
\hline IIIM & 1.19 & 1.09 & $1.03,1.16$ & 0.00 & 1.19 & 1.10 & $1.04,1.18$ & 0.00 \\
\hline IV/V & 1.29 & 1.13 & $1.07,1.20$ & 0.00 & 1.17 & 1.05 & $0.98,1.11$ & 0.14 \\
\hline Unclassified & 1.57 & 1.38 & $1.30,1.48$ & 0.00 & 1.30 & 1.17 & $1.11,1.24$ & 0.00 \\
\hline \multicolumn{9}{|l|}{ Tenure and car availability } \\
\hline Owner occupation, with car & 1.00 & 1.00 & & & 1.00 & 1.00 & & \\
\hline Owner occupation, no car & 1.21 & 1.15 & $1.09,1.22$ & 0.00 & 1.12 & 1.14 & $1.08,1.19$ & 0.00 \\
\hline Renting, with car & 1.19 & 1.15 & $1.09,1.22$ & 0.00 & 1.17 & 1.14 & $1.06,1.22$ & 0.00 \\
\hline Renting, no car & 1.48 & 1.38 & $1.32,1.45$ & 0.00 & 1.31 & 1.33 & $1.27,1.39$ & 0.00 \\
\hline Communal & 2.05 & 1.81 & $1.53,2.12$ & 0.00 & 2.75 & 2.67 & $2.39,2.96$ & 0.00 \\
\hline
\end{tabular}

*Adjusted for five year age and time bands. †Adjusted for five year age and time bands and the other factors listed.

others initially, but after a few years the difference would be considerably reduced or disappear. A further indicator of health selection would arise if those who had moved shortly before the census had a differing mortality risk in the short-term than those who had not, especially if this move coincided with a transition in socioeconomic status. Information on residence in an institution was only available at the time of the census and therefore it was not possible to undertake an equivalent check for health selection effects on risk of institutional residence.

\section{Results}

DESCRIPTIONS OF THE POPULATIONS (TABLE 1) There were 43092 men and 51278 women aged $55-74$ in the LS sample in 1971. Their characteristics are shown in the columns labelled A in table 1. Analyses of mortality by change in socioeconomic and demographic circumstance were confined to the $60 \%$ of men and $72 \%$ of women in the community in both 1971 and 1981 so that socioeconomic changes could be measured. Their baseline characteristics differed little from those of the sample in table 1 except that men staying in the community were more likely to be in a household with access to a car $(61 \%$ compared with $56 \%$ for men aged 55-64 in 1971 and 44\% compared with $37 \%$ for older men) and older men were more likely to be in owner-occupied accommodation (58\% against 52\%). Analyses of institutional residence in 1991 were further restricted to those still alive in 1991 ( $41 \%$ of men and $54 \%$ of women who were in the community in 1981). The 1971 characteristics of this group are shown in the columns labelled B. These survivors were disproportionately from the more privileged groups.

TWENTY ONE YEAR MORTALITY RISK RELATIVE TO CIRCUMSTANCES IN 1971 (TABLE 2)

By the end of 1992, 70\% of men aged 55-64 and $93 \%$ of those aged $65-74$ had died. The equivalent figures for women were $49 \%$ and $84 \%$.

People in households renting accommodation and without access to a car in 1971 had a $35-45 \%$ higher mortality rate than those in owner occupied homes with a car available. Most groups with intermediate socioeconomic 
Table 3 Intercensal changes in demographic and socioeconomic circumstances for people: $(A)$ in the community in 1971 and 1981 and (B) also alive in 1991

\begin{tabular}{|c|c|c|c|c|c|c|c|c|}
\hline \multirow[b]{2}{*}{ Transition factor 1971-1981 } & \multicolumn{4}{|c|}{ Men: age in 1971} & \multicolumn{4}{|c|}{ Women: age in 1971} \\
\hline & $55-64$ & & $65-74$ & & $55-64$ & & $65-74$ & \\
\hline & A & B & A & B & A & B & A & B \\
\hline Marital status & $\%$ & $\%$ & $\%$ & $\%$ & $\%$ & $\%$ & $\%$ & $\%$ \\
\hline Married in 1971 and 1981 & 77 & 81 & 64 & 70 & 48 & 50 & 23 & 26 \\
\hline Formed relationship & 2 & 2 & 2 & 3 & 2 & 2 & 1 & 1 \\
\hline Single throughout & 5 & 4 & 4 & 2 & 8 & 8 & 11 & 12 \\
\hline Marriage ended after 1971 & 11 & 9 & 20 & 17 & 23 & 22 & 28 & 28 \\
\hline Marriage ended before 1971 & 5 & 4 & 10 & 8 & 19 & 18 & 37 & 33 \\
\hline Living arrangements & $\%$ & $\%$ & $\%$ & $\%$ & $\%$ & $\%$ & $\%$ & $\%$ \\
\hline Not alone in 1971 and 1981 & 85 & 87 & 76 & 80 & 63 & 64 & 44 & 44 \\
\hline Ceased to be alone & 1 & 1 & 2 & 1 & 2 & 2 & 3 & 3 \\
\hline Became alone & 9 & 8 & 15 & 13 & 22 & 22 & 25 & 26 \\
\hline Alone in 1971 and 1981 & 4 & 4 & 7 & 6 & 13 & 12 & 28 & 27 \\
\hline Housing tenure & $\%$ & $\%$ & $\%$ & $\%$ & $\%$ & $\%$ & $\%$ & $\%$ \\
\hline Owner occupation in 1971 and 1981 & 51 & 55 & 53 & 58 & 49 & 51 & 47 & 52 \\
\hline Moved into owner occupation & 6 & 6 & 4 & 4 & 6 & 6 & 5 & 5 \\
\hline Moved out of owner occupation & 3 & 3 & 5 & 5 & 4 & 4 & 6 & 4 \\
\hline In rented accommodation & 40 & 36 & 38 & 34 & 42 & 40 & 42 & 39 \\
\hline Car availability & $\%$ & $\%$ & $\%$ & $\%$ & $\%$ & $\%$ & $\%$ & $\%$ \\
\hline Available in 1971 and 1981 & 50 & 57 & 31 & 40 & 34 & 36 & 18 & 20 \\
\hline Gained availability & 5 & 5 & 5 & 4 & 5 & 5 & 6 & 6 \\
\hline Lost availability & 11 & 9 & 13 & 10 & 15 & 15 & 12 & 13 \\
\hline No car in either year & 34 & 29 & 52 & 46 & 45 & 43 & 64 & 61 \\
\hline Changed address & & & & & & & & \\
\hline Not between 1971 and 1981 & 64 & & 67 & & 62 & & 65 & \\
\hline During first 9 years & 32 & & 30 & & 34 & & 32 & \\
\hline During last year & 4 & & 3 & & 4 & & 3 & \\
\hline Number & 18677 & 8934 & 7302 & 1514 & 24271 & 15437 & 13539 & 4599 \\
\hline
\end{tabular}

circumstances had an excess risk of about $15-20 \%$. Women and older men living in institutions had higher mortality than those in private households. There was only a clear inverse association between social class and mortality among younger men although in each age group subjects without a social class generally had the highest risk of dying in the 21 year period.

For men there were marginal excess risks of dying if not married in 1971 and living alone but excess risks of $20-35 \%$ if living with others. For women there was little association between 21 year mortality and sociodemographic characteristics (marital status and whether living alone) except an increased risk for older widowed women living with others.

Once risks are adjusted for all the variables, differences in mortality risks are smaller compared with those calculated for each variable adjusting only for time and age. This can be seen by comparing the first and second columns for each subgroup in table 2. This suggests that the variables are correlated with each other. For example, being unmarried seems to carry excess risk of mortality for women in the simpler model but not in the fuller model. Non-married women were much more likely to be in communal establishments, in households without access to a car and of unclassified social class than married women.

Relative risks of mortality after 1975 were lower than for the period up to 1975, but still statistically significant, for various groups (not shown): those in institutional residence, younger men with no social class, and older men without a car. The excess risk was statistically significant only in the first period for older men renting with a car and older divorced men not living alone. Mortality rate was statistically significantly raised only in the later period for older divorced men living alone and for men in manual social classes.
INTER-CENSUS CHANGES IN CIRCUMSTANCES (TABLE 3)

The most common changes experienced were losing a spouse and starting to live alone, women being more likely to experience both (column A). Bereavement accounted for $79 \%$ of the loss of spouse for men and $92 \%$ for women. About one in 10 men and women changed housing tenure. Car availability for the household changed for about one in six men and one in five women, more losing than gaining it. The prevalence of inter-census changes experienced by the survivors used in the analyses of institutional residence were of similar orders of magnitude (column B).

MORTALITY RISK 1981-1992 RELATIVE TO CHANGES IN CIRCUMSTANCES 1971-1981 (TABLES 4, 5)

In general, being disadvantaged in 1971 and in 1981 was associated with an increased risk of dying compared with those who were advantaged in both years. Being alone in both years was associated with a $10-20 \%$ reduced risk of dying.

Moving from owner occupied into rented accommodation carried an increased mortality risk similar to that found among those staying in rented accommodation throughout. The excess was not statistically different from zero for men aged 65-74 in 1971. Similarly, for men loss of household car availability during the inter-census period carried an increased mortality risk at least as high as lack of access to a car in both years. Losing household access to a car was less important for younger women and unimportant for older women.

Losing one's spouse between censuses was associated with risk ratios for dying within the subsequent 12 years of the order of 1.1-1.3, very similar to the risk ratios for people who had lost their spouse before 1971. The risks of mortality if starting to live alone were 10-20\% less than for those who lived with others 
Table 4 Risk ratio (RR), 95\% confidence intervals (CI) and p values for mortality 1981-1992 by intercensal changes in demographic and socioeconomic circumstances

\begin{tabular}{|c|c|c|c|c|c|c|c|c|}
\hline \multirow[b]{2}{*}{ Sex and factor } & \multicolumn{4}{|c|}{$55-64$ years in 1971} & \multicolumn{4}{|c|}{$65-74$ years in 1971} \\
\hline & $R R^{\star}$ & $\begin{array}{l}\text { Adjusted } t \\
R R\end{array}$ & $95 \% C I$ & p value & $R R^{\star}$ & $\begin{array}{l}\text { Adjusted } t \\
R R\end{array}$ & $95 \% C I$ & $p$ value \\
\hline \multicolumn{9}{|l|}{ Men } \\
\hline Married in 1971 and 1981 & 1.00 & 1.00 & & & 1.00 & 1.00 & & \\
\hline Formed relationship & 0.95 & 0.92 & $0.78,1.09$ & 0.35 & 0.95 & 0.91 & $0.72,1.14$ & 0.44 \\
\hline Single throughout & 1.15 & 1.13 & $1.00,1.27$ & 0.05 & 1.06 & 1.14 & $0.96,1.33$ & 0.13 \\
\hline Marriage ended after 1971 & 1.25 & 1.28 & $1.17,1.40$ & 0.00 & 1.16 & 1.22 & $1.10,1.35$ & 0.00 \\
\hline Marriage ended by 1971 & 1.29 & 1.28 & $1.14,1.44$ & 0.00 & 1.14 & 1.25 & $1.10,1.41$ & 0.00 \\
\hline \multicolumn{9}{|l|}{ Living arrangements } \\
\hline Not alone in 1971 and 1981 & 1.00 & 1.00 & & & 1.00 & 1.00 & & \\
\hline Ceased to be alone & 1.09 & 1.08 & $0.87,1.32$ & 0.49 & 1.12 & 1.11 & $0.86,1.39$ & 0.43 \\
\hline Became alone & 1.20 & 0.88 & $0.79,0.98$ & 0.02 & 1.12 & 0.91 & $0.79,1.03$ & 0.12 \\
\hline Alone in 1971 and 1981 & 1.17 & 0.88 & $0.76,1.01$ & 0.08 & 1.05 & 0.83 & $0.70,0.97$ & 0.02 \\
\hline \multicolumn{9}{|l|}{ Housing tenure } \\
\hline In owner occupation & 1.00 & 1.00 & & & 1.00 & 1.00 & & \\
\hline \multicolumn{9}{|l|}{ Moved } \\
\hline to owner-occupation & 1.11 & 1.07 & $0.98,1.17$ & 0.12 & 1.05 & 1.02 & $0.88,1.17$ & 0.76 \\
\hline out of owner-occupation & 1.33 & 1.19 & $1.06,1.33$ & 0.00 & 1.12 & 1.04 & $0.91,1.19$ & 0.54 \\
\hline In rented accommodation & 1.34 & 1.20 & $1.15,1.26$ & 0.00 & 1.11 & 1.04 & $0.97,1.10$ & 0.29 \\
\hline \multicolumn{9}{|l|}{ Car availability } \\
\hline Available in 1971 and 1981 & 1.00 & 1.00 & & & 1.00 & 1.00 & & \\
\hline Gained availability & 1.27 & 1.20 & $1.09,1.31$ & 0.00 & 1.33 & 1.26 & $1.10,1.43$ & 0.00 \\
\hline Lost availability & 1.51 & 1.43 & $1.34,1.52$ & 0.00 & 1.35 & 1.36 & $1.25,1.47$ & 0.00 \\
\hline No car in either year & 1.43 & 1.32 & $1.26,1.39$ & 0.00 & 1.28 & 1.27 & $1.20,1.35$ & 0.00 \\
\hline \multicolumn{9}{|l|}{ Women } \\
\hline \multicolumn{9}{|l|}{ Marital status } \\
\hline Married in 1971 and 1981 & 1.00 & 1.00 & & & 1.00 & 1.00 & & \\
\hline Formed relationship & 1.03 & 1.03 & $0.87,1.22$ & 0.76 & 0.90 & 0.89 & $0.38,1.13$ & 0.34 \\
\hline Single throughout & 1.10 & 1.13 & $1.03,1.24$ & 0.01 & 1.05 & 1.15 & $1.05,1.25$ & 0.00 \\
\hline Marriage ended after 1971 & 1.13 & 1.22 & $1.13,1.32$ & 0.00 & 1.05 & 1.12 & $1.03,1.22$ & 0.01 \\
\hline Marriage ended before 1971 & 1.20 & 1.22 & $1.13,1.32$ & 0.00 & 1.13 & 1.26 & $1.17,1.35$ & 0.00 \\
\hline \multicolumn{9}{|l|}{ Living arrangements } \\
\hline Not alone in 1971 and 1981 & 1.00 & 1.00 & & & 1.00 & 1.00 & & \\
\hline Ceased to be alone & 1.08 & 0.96 & $0.82,1.13$ & 0.65 & 1.09 & 1.00 & $0.86,1.15$ & 0.98 \\
\hline Became alone & 1.04 & 0.83 & $0.76,0.90$ & 0.00 & 0.98 & 0.89 & $0.82,0.97$ & 0.01 \\
\hline Alone in 1971 and 1981 & 1.13 & 0.89 & $0.81,0.98$ & 0.01 & 0.99 & 0.79 & $0.73,0.86$ & 0.00 \\
\hline \multicolumn{9}{|l|}{ Housing tenure } \\
\hline In owner occupation & 1.00 & 1.00 & & & 1.00 & 1.00 & & \\
\hline \multicolumn{9}{|l|}{ Moved } \\
\hline to owner occupation & 1.10 & 1.06 & $0.97,1.18$ & 0.20 & 1.04 & 1.00 & $0.89,1.12$ & 0.99 \\
\hline out of owner occupation & 1.22 & 1.17 & $1.05,1.31$ & 0.01 & 1.26 & 1.26 & $1.14,1.39$ & 0.00 \\
\hline In rented accommodation & 1.30 & 1.22 & $1.16,1.28$ & 0.00 & 1.16 & 1.14 & $1.08,1.19$ & 0.00 \\
\hline \multicolumn{9}{|l|}{ Car availability } \\
\hline Available in 1971 and 1981 & 1.00 & 1.00 & & & 1.00 & 1.00 & & \\
\hline Gained availability & 1.18 & 1.08 & $0.97,1.19$ & 0.18 & 1.11 & 1.04 & $0.93,1.17$ & 0.46 \\
\hline Lost availability & 1.16 & 1.13 & $1.05,1.21$ & 0.00 & 0.99 & 1.01 & $0.92,1.10$ & 0.91 \\
\hline No car in either year & 1.31 & 1.21 & $1.14,1.28$ & 0.00 & 1.13 & 1.12 & $1.05,1.20$ & 0.00 \\
\hline
\end{tabular}

*Adjusted for 3 year age and time bands. †Adjusted for 3 year age and time bands and all other factors in the table.

throughout. There was substantial overlap between those who lost their spouse and those who started to live alone, which may explain the difference in relative risk estimates between the simpler and fuller models. Starting to live alone seemed to be an adverse factor for men and neutral for women in the simpler models and protective in the full model, whereas losing a spouse seemed to be more of an adverse factor in the full model than the separate model.

Those whose circumstances had "improved" tended to have similar risk of mortality to people who remained in more fortunate circumstances. However, changing to being in a household with a car carried a higher risk for men.

Table 5 shows relative risks of dying in the periods 1981-1984 and 1985-1992 according to inter-census changes in circumstances. Relative risks in the later period were generally closer to 1.0 than those for the earlier period. The relative risks were statistically significant (or marginally so) in the earlier period but not the later one for older women who moved into owner occupied households, and for older people who moved into households with a car or lost their spouse between the two censuses.
There was a statistically significant reduced risk of mortality only in the earlier period for older women who started to live alone and for men who lived alone in both periods. There was little dilution of excess risk for those who lost access to a car or did not have access to a car at either census and for those who moved into, or remained in, rented accommodation. The exception to this was younger women who moved into rented accommodation between 1971 and 1981. Having moved either in the year before the census or in the nine years before that had no impact on mortality risk nor acted as a confounder for the other factors (not shown).

RISK OF BEING IN AN INSTITUTION IN 1991 BY CIRCUMSTANCES IN 1971 (TABLE 6)

Proportionately more women than men were in institutions in 1991; $6 \%$ of women aged 55-64 in 1971 and $23 \%$ of those aged $65-74$ compared with $3 \%$ and $14 \%$ of men in these age groups $(p<0.0001)$. Being in a household without access to a car was associated with higher risk of being in an institution in 1991, regardless of housing tenure, sex and age. Men also in rented accommodation carried a $90 \%$ 
Table 5 Risk ratio (RR) and p values for early (1981-4) and late (1985-92) mortality by intercensal changes in socioeconomic and demographic circumstances (adjusted for three year time and age bands and all other factors listed)

\begin{tabular}{|c|c|c|c|c|c|c|c|c|c|c|c|c|c|c|c|c|}
\hline \multirow[b]{4}{*}{ Factor } & \multicolumn{8}{|l|}{ Men } & \multicolumn{8}{|c|}{ Women } \\
\hline & \multicolumn{4}{|c|}{$55-64$ years in 1971} & \multicolumn{4}{|c|}{$65-74$ years in 1971} & \multicolumn{4}{|c|}{$55-64$ years in 1971} & \multicolumn{4}{|c|}{$65-74$ years in 1971} \\
\hline & \multicolumn{2}{|c|}{$1981-84$} & \multicolumn{2}{|c|}{ 1985-92 } & \multicolumn{2}{|c|}{$1981-84$} & \multicolumn{2}{|c|}{ 1985-92 } & \multicolumn{2}{|c|}{$1981-84$} & \multicolumn{2}{|c|}{$1985-92$} & \multicolumn{2}{|c|}{$1981-84$} & \multicolumn{2}{|c|}{ 1985-92 } \\
\hline & $R R$ & $p$ & $R R$ & $p$ & $R R$ & $p$ & $R R$ & $p$ & $R R$ & $p$ & $R R$ & $p$ & $R R$ & $p$ & $R R$ & $p$ \\
\hline \multicolumn{17}{|l|}{ Marital status } \\
\hline Married in 1971 and 1981 & 1.00 & & 1.00 & & 1.00 & & 1.00 & & 1.00 & & 1.00 & & 1.00 & & 1.00 & \\
\hline Formed relationship & 0.96 & 0.80 & 0.92 & 0.36 & 0.87 & 0.48 & 0.95 & 0.66 & 0.92 & 0.70 & 1.05 & 0.60 & 1.05 & 0.83 & 0.85 & 0.22 \\
\hline Single throughout & 1.20 & 0.11 & 1.08 & 0.20 & 1.13 & 0.36 & 1.10 & 0.26 & 1.25 & 0.04 & 1.10 & 0.07 & 1.21 & 0.03 & 1.10 & 0.03 \\
\hline Marriage ended after 1971 & 1.14 & 0.18 & 1.30 & 0.00 & 1.30 & 0.00 & 1.11 & 0.06 & 1.27 & 0.01 & 1.20 & 0.00 & 1.25 & 0.01 & 1.06 & 0.19 \\
\hline $\begin{array}{l}\text { Marriage ended before } 1971 \\
\text { Living arrangements }\end{array}$ & 1.46 & 0.00 & 1.19 & 0.01 & 1.35 & 0.00 & 1.12 & 0.08 & 1.23 & 0.02 & 1.21 & 0.00 & 1.35 & 0.00 & 1.18 & 0.00 \\
\hline Not alone in 1971 and 1981 & 1.00 & & 1.00 & & 1.00 & & 1.00 & & 1.00 & & 1.00 & & 1.00 & & 1.00 & \\
\hline Ceased to be alone & 1.08 & 0.68 & 1.06 & 0.59 & 1.00 & 0.99 & 1.13 & 0.32 & 0.81 & 0.28 & 1.00 & 0.97 & 0.93 & 0.55 & 1.03 & 0.71 \\
\hline Became alone & 0.85 & 0.12 & 0.91 & 0.09 & 0.91 & 0.30 & 0.93 & 0.26 & 0.74 & 0.00 & 0.86 & 0.00 & 0.78 & 0.00 & 0.95 & 0.22 \\
\hline Alone in 1971 and 1981 & 0.76 & 0.05 & 0.94 & 0.40 & 0.73 & 0.01 & 0.93 & 0.39 & 0.87 & 0.17 & 0.90 & 0.03 & 0.75 & 0.00 & 0.84 & 0.00 \\
\hline \multicolumn{17}{|l|}{ Housing tenure } \\
\hline \multicolumn{17}{|l|}{ Owner occupation in 1971 and } \\
\hline 1981 & 1.00 & & 1.00 & & 1.00 & & 1.00 & & 1.00 & & 1.00 & & 1.00 & & 1.00 & \\
\hline Moved into owner occupation & 1.09 & 0.32 & 1.06 & 0.23 & 0.96 & 0.71 & 1.05 & 0.51 & 1.12 & 0.33 & 1.05 & 0.34 & 1.27 & 0.02 & 0.91 & 0.11 \\
\hline Moved out of owner occupation & 1.18 & 0.15 & 1.18 & 0.01 & 1.08 & 0.43 & 1.01 & 0.88 & 1.51 & 0.00 & 1.09 & 0.14 & 1.28 & 0.01 & 1.21 & 0.00 \\
\hline $\begin{array}{l}\text { In rented accommodation } \\
\text { Car availability }\end{array}$ & 1.20 & 0.00 & 1.18 & 0.00 & 1.06 & 0.23 & 1.01 & 0.71 & 1.35 & 0.00 & 1.18 & 0.00 & 1.20 & 0.00 & 1.09 & 0.00 \\
\hline Available in 1971 and 1981 & 1.00 & & 1.00 & & 1.00 & & 1.00 & & 1.00 & & 1.00 & & 1.00 & & 1.00 & \\
\hline Gained availability & 1.19 & 0.07 & 1.18 & 0.00 & 1.43 & 0.00 & 1.10 & 0.19 & 1.18 & 0.16 & 1.05 & 0.42 & 1.22 & 0.06 & 0.98 & 0.67 \\
\hline Lost availability & 1.58 & 0.00 & 1.32 & 0.00 & 1.29 & 0.00 & 1.28 & 0.00 & 1.15 & 0.10 & 1.12 & 0.00 & 0.96 & 0.63 & 1.02 & 0.70 \\
\hline No car in either year & 1.31 & 0.00 & 1.29 & 0.00 & 1.27 & 0.00 & 1.19 & 0.00 & 1.28 & 0.00 & 1.18 & 0.00 & 1.15 & 0.03 & 1.09 & 0.01 \\
\hline
\end{tabular}

excess risk of institutionalisation and women a $40-45 \%$ excess risk. However, the most striking differences for those aged 55-64 in 1971 were by marital status. Being single was an important predictor of long term risk (twofold to threefold excess risk), irrespective of living alone or not. In this age cohort, the divorced or separated men had around a threefold excess risk and widowed men who were not living alone a relative risk of 2.3. In the older age cohort (65-74 years in 1971), a rather different pattern emerged. For single and widowed men, only those who were not living alone in 1971 were at increased risk while being divorced or separated had no influence. Only older single women living alone were at increased risk $(\mathrm{RR}=1.5)$ while widowed women who were not living alone had a $40 \%$ reduction in risk.

RISK OF BEING IN AN INSTITUTION AT 1991

CENSUS BY INTER-CENSUS CHANGES (TABLE 7)

Living in rented accommodation at both census dates was associated with an increased risk for both men and women in the younger age group (55 to 64 in 1971). For both men and women and both age groups, lack of availability of a car at both census dates increased risk by around $30 \%$ to $80 \%$. Moving out of owner occupation into rented accommodation was a significant risk factor for women but not for men. Loss of household access to a car was associated with an increased risk of institutional residence only for the younger cohort.

For men, loss of a spouse was associated with a twofold to fourfold increase in risk, especially for men who lost their spouse before 1971. For women, loss of a spouse was not a significant risk factor. Men and women in the age group 55-64 years in 1971 and who were single at both census points were at an increased risk of being in an institution, most strikingly for men $(R R=5)$. Very elderly women who were alone at both census dates
KEY POINTS

- Middle aged and older people in the least privileged socioeconomic circumstances have the highest long term risks of mortality and institutional residence.

- Women are at higher risk of institutional residence than men.

- Marital status is a strong factor in risk of institutional residence for men, single men having particularly high relative risks.

- Loss of favourable socioeconomic circumstances in retirement is associated with an increased risk of mortality and of institutional residence.

- People who are alone or become alone do not have an excess risk of mortality once other circumstances are taken into account.

$(R R=1.5)$ were at increased risk of being in an institution in 1991 but younger men who started to live alone were at reduced risk $(\mathrm{R} R=0.5)$. Comparison between the adjusted and unadjusted odds ratios shows some substantial changes with respect to estimated effects of living arrangements for men. In general, adverse effects of living alone largely disappeared after adjustment for marital status, housing tenure and car availability.

Few groups experiencing improvements in circumstances between 1971 and 1981 carried risks of institutional residence statistically different from those who were in the more favourable circumstances in both census years. Older men moving into owner occupied accommodation and older women ceasing to live alone were at increased risk of being in an institution in 1991. However, very elderly women who married in the inter-census period had a $65 \%$ reduction in risk. 
Table 6 Risk ratios (RR), 95\% CI and p values for being in an institution at the 1991 census by demographic and demographic circumstances in 1971

\begin{tabular}{|c|c|c|c|c|c|c|c|c|}
\hline & \multicolumn{4}{|c|}{ Age 55-64 in 1971} & \multicolumn{4}{|c|}{ Age 65-74 in 1971} \\
\hline & $R R^{\star}$ & Adj $R R t$ & $95 \% C I$ & $p$ & $R R^{\star}$ & Adj RRt & $95 \% C I$ & $p$ \\
\hline \multicolumn{9}{|l|}{ Men } \\
\hline \multicolumn{9}{|l|}{ Marital status/whether alone } \\
\hline Married/cohabiting & 1.00 & 1.00 & & & 1.00 & 1.00 & & \\
\hline \multicolumn{9}{|l|}{ Single } \\
\hline alone & 3.27 & 2.67 & $1.50,4.75$ & 0.00 & 0.46 & 0.42 & $0.10,1.80$ & 0.24 \\
\hline not alone & 3.98 & 3.54 & $2.17,5.77$ & 0.00 & 2.84 & 3.00 & $1.19,7.57$ & 0.02 \\
\hline \multicolumn{9}{|l|}{ Widowed } \\
\hline alone & 1.80 & 1.59 & $0.76,3.29$ & 0.22 & 1.54 & 1.44 & $0.79,2.62$ & 0.23 \\
\hline not alone & 2.32 & 2.34 & $1.12,4.88$ & 0.02 & 2.36 & 2.52 & $1.21,5.25$ & 0.01 \\
\hline \multicolumn{9}{|l|}{ Divorced/separated } \\
\hline alone & 3.15 & 2.73 & $1.35,5.53$ & 0.00 & 0.77 & 0.69 & $0.08,5.59$ & 0.73 \\
\hline not alone & 2.79 & 2.83 & $1.41,5.69$ & 0.00 & 1.09 & 0.99 & $0.28,3.44$ & 0.99 \\
\hline \multicolumn{9}{|l|}{ Social class $\neq$} \\
\hline $\mathrm{I} / \mathrm{II}$ & 1.00 & 1.00 & & & 1.00 & 1.00 & & \\
\hline IIIN & 1.29 & 1.13 & $0.73,1.75$ & 0.60 & 0.91 & 0.76 & $0.45,1.29$ & 0.31 \\
\hline IIIM & 0.97 & 0.79 & $0.55,1.14$ & 0.21 & 0.82 & 0.63 & $0.39,1.00$ & 0.05 \\
\hline IV/V & 1.62 & 1.13 & $0.78,1.62$ & 0.53 & 1.31 & 0.93 & $0.60,1.46$ & 0.76 \\
\hline Unclassified $₫$ & 2.42 & 1.76 & $0.94,3.29$ & 0.08 & 1.63 & 1.27 & $0.70,2.30$ & 0.42 \\
\hline \multicolumn{9}{|l|}{ Tenure and car availability } \\
\hline Owner occupation, with car & 1.00 & 1.00 & & & 1.00 & 1.00 & & \\
\hline Owner occupation, no car & 1.69 & 1.54 & $1.05,2.26$ & 0.03 & 1.56 & 1.73 & $1.15,2.59$ & 0.01 \\
\hline Renting, with car & 1.47 & 1.47 & $1.03,2.09$ & 0.03 & 1.16 & 1.24 & $0.72,2.12$ & 0.44 \\
\hline Renting, no car & 2.16 & 1.89 & $1.34,2.67$ & 0.00 & 1.74 & 1.94 & $1.28,2.94$ & 0.00 \\
\hline \multicolumn{9}{|l|}{ Women } \\
\hline \multicolumn{9}{|l|}{ Marital status/whether alone } \\
\hline Married/cohabiting & 1.00 & 1.00 & & & 1.00 & 1.00 & & \\
\hline \multicolumn{9}{|l|}{ Single } \\
\hline alone & 2.61 & 2.41 & $1.86,3.12$ & 0.00 & 1.78 & 1.54 & $1.17,2.04$ & 0.00 \\
\hline not alone & 1.90 & 1.73 & $1.30,2.30$ & 0.00 & 1.27 & 1.15 & $0.85,1.57$ & 0.37 \\
\hline \multicolumn{9}{|l|}{ Widowed } \\
\hline alone & 1.43 & 1.07 & $0.84,1.36$ & 0.60 & 1.20 & 0.96 & $0.78,1.19$ & 0.74 \\
\hline not alone & 1.05 & 0.85 & $0.63,1.13$ & 0.26 & 0.65 & 0.59 & $0.43,0.80$ & 0.00 \\
\hline \multicolumn{9}{|l|}{ Divorced/separated } \\
\hline alone & 1.57 & 1.08 & $0.67,1.74$ & 0.74 & 1.26 & 0.99 & $0.58,1.66$ & 0.96 \\
\hline not alone & 1.60 & 1.11 & $0.74,1.68$ & 0.62 & 0.61 & 0.52 & $0.26,1.05$ & 0.07 \\
\hline \multicolumn{9}{|l|}{ Social class $\neq$} \\
\hline $\mathrm{I} / \mathrm{II}$ & 1.00 & 1.00 & & & 1.00 & 1.00 & & \\
\hline IIIN & 1.28 & 1.10 & $0.84,1.44$ & 0.48 & 1.27 & 1.16 & $0.88,1.53$ & 0.28 \\
\hline IIIM & 1.28 & 1.26 & $0.99,1.60$ & 0.06 & 1.06 & 1.00 & $0.77,1.30$ & 0.98 \\
\hline IV/V & 1.48 & 1.34 & $1.06,1.70$ & 0.02 & 1.07 & 0.97 & $0.75,1.25$ & 0.82 \\
\hline Unclassified $\$$ & 2.08 & 1.85 & $1.44,2.38$ & 0.00 & 1.22 & 1.23 & $0.97,1.57$ & 0.09 \\
\hline \multicolumn{9}{|l|}{ Tenure and car availability } \\
\hline Owner occupation, with car & 1.00 & 1.00 & & & 1.00 & 1.00 & & \\
\hline Owner occupation, no car & 1.54 & 1.26 & $1.03,1.55$ & 0.02 & 1.37 & 1.25 & $1.02,1.54$ & 0.03 \\
\hline Renting, with car & 1.03 & 1.01 & $0.79,1.28$ & 0.96 & 0.95 & 0.98 & $0.71,1.36$ & 0.91 \\
\hline Renting, no car & 1.76 & 1.45 & $1.20,1.75$ & 0.00 & 1.49 & 1.39 & $1.13,1.71$ & 0.00 \\
\hline
\end{tabular}

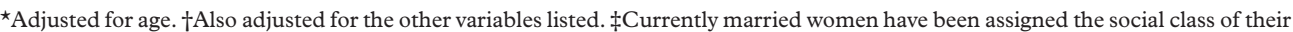
husband, other women their own social class. \$Those who could not be assigned a class either because of no occupation or inadequate information.

\section{Discussion}

Long term follow up studies can provide unique insights into risks associated with living patterns at an earlier age. The additional advantage of the LS is the linking of successive censuses that provide a better picture of individuals' circumstances as they move through life than a measurement taken at a single point in time.

Being in rented accommodation and in a household without access to a car was associated with increased risks both of death during the follow up period and of institutional residence in 1991. Previous studies have shown that these factors are associated with mortality for people aged 65 and over at death for up to 10 years (rate ratios of magnitude of $1.2-1.3$ for being an local authority tenant or for lacking a car $)^{213}$ and social class for men for up to 19 years ${ }^{14}$ after baseline. Being without a car or being in rented accommodation not only has a higher risk of death and moving to an institution but is also associated with a poorer self perception of health. ${ }^{15}$ It has been argued that socioeconomic differences may disappear because of selective survival ${ }^{15}$ but our results show that they persist for over 20 years, even when the absolute mortality risk is over $90 \%$. Similarly, the Whitehall study showed that employment grade had a continued influence on mortality 25 years later. ${ }^{16}$

Our results agree with some patterns previously reported demonstrating the importance of marital status and living arrangements on institutional risk in elderly people. ${ }^{17-22} \mathrm{~A}$ finding of many studies is the high risk for people who have never married. ${ }^{192122}$ It is plausible that single people move into institutions at an earlier stage of chronic illness than those with spouses or children and analyses of changes in SMR over time support this. ${ }^{23}$ The adverse effect of widowhood is more controversial with some studies finding an association for both widowed elderly men and women, ${ }^{19}{ }^{22}$ others finding no association once living circumstances have been taken into account. ${ }^{18}$ Being single had a greater negative impact in men than women. Women who by 1971 were widowed, divorced or separated did not have an increased risk of institutional residence in 1991; indeed widowed women who were aged 65-74 and living with others in 1971 were at 
Table 7 Risk ratios (RR), 95\% CI and p values for being in an institution at the 1991 census by intercensal changes in demographic and socioeconomic factors

\begin{tabular}{|c|c|c|c|c|c|c|c|c|}
\hline & \multicolumn{4}{|c|}{ Age 55-64 in 1971} & \multicolumn{4}{|c|}{ Age 65-74 in 1971} \\
\hline & $R R^{\star}$ & $\operatorname{Adj} R R+$ & $95 \% C I$ & $p$ & $R R^{\star}$ & $\begin{array}{l}\text { Adj } \\
R R+\end{array}$ & $95 \% C I$ & $p$ \\
\hline \multicolumn{9}{|l|}{ Men } \\
\hline \multicolumn{9}{|l|}{ Marital status/whether alone } \\
\hline Married in 1971 and 1981 & 1.00 & 1.00 & & & 1.00 & 1.00 & & \\
\hline Formed relationship & 1.59 & 1.76 & $0.73,4.24$ & 0.21 & 0.72 & 1.21 & $0.32,4.59$ & 0.78 \\
\hline Single throughout & 4.14 & 4.95 & $3.06,8.00$ & 0.00 & 1.77 & 2.04 & $0.84,4.97$ & 0.12 \\
\hline Marriage ended after 1971 & 2.23 & 3.08 & $1.93,4.91$ & 0.00 & 2.23 & 1.92 & $1.11,3.31$ & 0.02 \\
\hline Marriage ended before 1971 & 3.54 & 4.59 & $2.70,7.82$ & 0.00 & 2.40 & 3.49 & $1.78,6.85$ & 0.00 \\
\hline \multicolumn{9}{|l|}{ Living arrangements } \\
\hline Not alone in 1971 and 1981 & 1.00 & 1.00 & & & 1.00 & 1.00 & & \\
\hline Ceased to be alone & 1.75 & 0.86 & $0.30,2.46$ & 0.77 & 2.31 & 0.24 & $0.03,2.21$ & 0.21 \\
\hline Became alone & 1.74 & 0.54 & $0.33,0.90$ & 0.02 & 0.32 & 1.23 & $0.69,2.18$ & 0.69 \\
\hline Alone in 1971 and 1981 & 2.91 & 0.61 & $0.34,1.08$ & 0.09 & 1.62 & 0.55 & $0.25,1.23$ & 0.15 \\
\hline \multicolumn{9}{|l|}{ Housing temure } \\
\hline Owner occupation 1971 and 1981 & 1.00 & 1.00 & & & 1.00 & 1.00 & & \\
\hline Moved into owner-occupation & 1.65 & 1.09 & $0.64,1.87$ & 0.75 & 1.49 & 2.04 & $1.02,4.06$ & 0.04 \\
\hline Moved out of owner-occupation & 1.23 & 1.20 & $0.61,2.39$ & 0.59 & 1.84 & 1.29 & $0.64,2.59$ & 0.47 \\
\hline In rented accommodation & 1.70 & 1.42 & $1.06,1.89$ & 0.02 & 1.29 & 1.06 & $0.75,1.50$ & 0.74 \\
\hline \multicolumn{9}{|l|}{ Car availability } \\
\hline Available in 1971 and 1981 & 1.00 & 1.00 & & & 1.00 & 1.00 & & \\
\hline Gained availability & 1.77 & 1.34 & $0.75,2.39$ & 0.33 & 1.23 & 1.07 & $0.47,2.44$ & 0.87 \\
\hline Lost availability & 1.54 & 1.56 & $1.03,2.37$ & 0.04 & 1.21 & 1.18 & $0.66,2.09$ & 0.57 \\
\hline No car in either year & 2.00 & 1.61 & $1.18,2.18$ & 0.00 & 1.74 & 1.77 & $1.21,2.60$ & 0.00 \\
\hline \multicolumn{9}{|l|}{ Women } \\
\hline \multicolumn{9}{|l|}{ Marital status/whether alone } \\
\hline Married in 1971 and 1981 & 1.00 & 1.00 & & & 1.00 & 1.00 & & \\
\hline Formed relationship & 1.24 & 1.24 & $0.71,2.18$ & 0.45 & 0.63 & 0.35 & $0.15,0.85$ & 0.02 \\
\hline Single throughout & 2.51 & 1.98 & $1.52,2.57$ & 0.00 & 1.68 & 1.19 & $0.90,1.58$ & 0.23 \\
\hline Marriage ended after 1971 & 1.41 & 1.18 & $0.91,1.53$ & 0.22 & 1.22 & 1.02 & $0.77,1.35$ & 0.90 \\
\hline Marriage ended before 1971 & 1.53 & 1.16 & $0.90,1.50$ & 0.26 & 1.16 & 0.75 & $0.57,0.98$ & 0.03 \\
\hline \multicolumn{9}{|l|}{ Living arrangements } \\
\hline Not alone in 1971 and 1981 & 1.00 & 1.00 & & & 1.00 & 1.00 & & \\
\hline Ceased to be alone & 1.44 & 0.92 & $0.54,1.59$ & 0.78 & 1.33 & 2.58 & $1.63,4.08$ & 0.00 \\
\hline Became alone & 1.15 & 1.07 & $0.83,1.37$ & 0.60 & 1.80 & 1.19 & $0.91,1.55$ & 0.20 \\
\hline Alone in 1971 and 1981 & 1.92 & 1.22 & $0.94,1.59$ & 0.13 & 1.49 & 1.50 & $1.16,1.94$ & 0.00 \\
\hline \multicolumn{9}{|l|}{ Housing tenure } \\
\hline Owner occupation 1971 and 1981 & 1.00 & 1.00 & & & 1.00 & 1.00 & & \\
\hline Moved into owner occupation & 2.01 & 0.86 & $0.60,1.23$ & 0.41 & 1.52 & 1.03 & $0.73,1.46$ & 0.87 \\
\hline Moved out of owner occupation & 0.86 & 1.73 & $1.28,2.33$ & 0.00 & 1.09 & 1.43 & $1.02,2.00$ & 0.04 \\
\hline In rented accommodation & 1.42 & 1.23 & $1.06,1.43$ & 0.01 & 1.22 & 1.10 & $0.94,1.29$ & 0.23 \\
\hline \multicolumn{9}{|l|}{ Car availability } \\
\hline Available in 1971 and 1981 & 1.00 & 1.00 & & & 1.00 & 1.00 & & \\
\hline Gained availability & 1.54 & 1.20 & $0.84,1.72$ & 0.32 & 1.15 & 0.99 & $0.68,1.44$ & 0.95 \\
\hline Lost availability & 1.30 & 1.36 & $1.07,1.73$ & 0.01 & 1.20 & 1.04 & $0.78,1.38$ & 0.81 \\
\hline No car in either year & 2.00 & 1.58 & $1.31,1.90$ & 0.00 & 1.57 & 1.32 & $1.06,1.64$ & 0.01 \\
\hline
\end{tabular}

*Adjusted for age. $†$ Also adjusted for other factors shown.

reduced risk. In contrast, men who were not married but living with others seemed to be at higher risk of institutional residence than those who were alone. It is not clear why this should be but may reflect on the care arrangements available.

It was anticipated that the effects of widowhood and living alone may be different for the two genders. ${ }^{24}$ Tests for interaction by gender confirmed that the relative risks of mortality and institutional residence from losing a spouse were greater for men than for women and that becoming alone was slightly more favourable with respect to mortality risk for women than for men. Some other studies have found gender differences in mortality by marital status and/or living arrangements. ${ }^{25}{ }^{26}$ Social network support may partially account for gender differences in marital status and health outcomes. $^{27}$

We hypothesised that deterioration in circumstances would increase risk of dying and institutional residence to the levels of those who had less favourable circumstances in both 1971 and 1981. Social class was dropped from consideration because it was not clear whether changes were real or an artefact of misreporting previous occupation. $^{28}$ There was some evidence that starting to live alone was associated with lower mortality and risk of institutionalisation than living with others. The "effects" of starting to live alone and, to a lesser extent, losing a spouse, differed between the separate and full models for both outcomes, possibly because the change to living alone is correlated with "adverse" changes in marital status and housing tenure and only the more robust lived alone. For housing tenure and car availability the data were more in line with the hypotheses although changing to a household with access to a car as well as changing to one without was associated with increased mortality risk for men.

Those who had lost a spouse between censuses and survived until 1984 or later no longer had excess risk of mortality. This suggests that there is an effect of being widowed that lasts a few years. However, we may not have captured the full short-term effects of losing a spouse as excess mortality from bereavement is greatest within months of the loss. ${ }^{29} 30$

Men incurred greater excess risks of 11 year mortality and for institutional residence than women in either losing or not having a car available to the household. In a cross sectional study of disability, lack of a car was strongly associated with men's disability but not women's. ${ }^{15}$ These gender differences may 
reflect relative importance of different facets of socioeconomic life to both everyday functioning and to self esteem, differences that may diminish with successive generations.

With older people it is difficult to disentangle the causes and consequences of ill health. Prior health status has been shown to be an important predictor of mortality ${ }^{31}$ although not so clearly for moving to an institution. ${ }^{18}$ We could not test for health selection effects for moving into an institution. They are likely to be considerably weakened over the 10-20 year period considered here, although they probably play some part, for example in explaining lower risks for women who marry in old age. For mortality we compared relative risks in the early years of the follow up period with the later years to see if changes over time suggested a health selection effect. The differences between relative mortality risks before and after 1975 are consistent with selection of acutely ill people into the unclassified social class or into institutions. (However, the mortality of this group remained significantly higher in these group after 1975 suggesting that chronic illness continues to take its toll.) The differences between earlier and later periods in relative risks of mortality by inter-census changes are consistent with apparent "improvement" in circumstances (for example, moving into owner occupied accommodation or into a household with a car) being prompted by ill health and need for informal care, particularly for the older generation. The results for starting to live alone or remaining alone suggest that relatively healthy people are able to live alone but over time they too develop illness.

With one exception, the results give no grounds for suspecting health selection as the reason for high mortality rates among those whose circumstances "deteriorated" or remained poor. Indeed, the adverse associations of deterioration in circumstances with risk of dying over an 11 year period may be underestimated because we omitted deaths of people who had moved into an institution before 1981. The exception was the group of younger women moving into rented accommodation - it is possible that this group included ill women moving into sheltered rented accommodation.

The apparent adverse effect of a deterioration in circumstance has also been found in an analysis of middle aged men, using the LS. An increase in mortality rate has been found among those who moved from a higher to lower social class - their mortality rate was between the rate of their class of origin and that of the class of destination. Conversely, those who moved up a class improved their mortality risk but not to a level as low as that of their class of destination. ${ }^{6}$ Our results add to evidence that changes in socioeconomic circumstances during adult life and old age are associated with changes in mortality risk.

Generally there were fewer statistically significant results for the older cohorts than the younger ones, partly because of the reduced statistical power from smaller numbers. Many of the relative risk estimates were close to 1.00 suggesting some attenuation of differences as people survive into very old age (the older people were aged 85-94 years in 1991). Given the advanced age of the older cohort in 1991 it is remarkable that there were still any associations between health outcomes and socioeconomic factors.

The LS omits any information on lifestyle risk factors such as smoking and physical exercise. While lifestyle factors are still relevant at least in early old age ${ }^{32}{ }^{33}$ they would not necessarily account for all the association between socioeconomic factors and mortality. In the Whitehall Study a wide range of behavioural, biological and morbidity factors did not fully account for the mortality differentials by grade and car availability in middle age $\mathrm{a}^{34}$ nor did smoking, alcohol consumption and sedentary lifestyle account for morbidity differentials by income in a study of older Canadians in the community. ${ }^{35}$ Moreover, lifestyle differences may in themselves be consequences of socioeconomic and sociodemographic circumstances.

It is possible that some people in sheltered housing were counted as being in the community in 1971 and in an institution in 1981 or vice versa. This could distort the institution figures a little but is not expected to make a substantial difference. The LS does not pick up those who entered an institution between census dates and died before the next census. The percentage of all those aged 65-74 in 1971 who ever entered an institution would be substantially higher than the percentage of survivors in an institution in 1991. The average length of stay in a home is two to three years ${ }^{36}$ and if people stay long enough to become resident they are likely to die there. It seems far more likely that the relative risks for the socioeconomically disadvantaged of entering an institution will be underestimated than overestimated. It is of concern if disadvantaged people are in greater need of institutional care as, with reduced NHS long stay care and increased residential and nursing home care especially in the private sector, ${ }^{36}{ }^{37}$ the economic burden of residential care of the elderly has been transferred to local authorities and, through means testing, back to elderly people and their families.

This study, by showing the percentages who changed housing tenure and car availability and how these affect health outcomes, has implications for the choice of socioeconomic measure among people who are well beyond working age. Social class was affected by selection of the ill into the unclassified group; also it was not as useful a predictor as other factors and is subject to misclassification. Housing tenure and car availability are not so prone to misclassification but it now seems that studies may benefit from taking into account status at more than one point in time.

In conclusion, this study confirms the persistence of an impact of socioeconomic group measured in middle age right into extremes of old age some 20 years later. Moreover, the Longitudinal Study provides a unique opportunity to document the effect on 
mortality of changes in socioeconomic circumstances occurring as people move into and through retirement. These results demonstrate persistence of inequalities in health related outcomes throughout old age, both in those with unfavourable circumstances in mid-life and in those who, in later life, have lost earlier advantages.

Funding: Department of Health.

Conflicts of interest: none.

We thank the Longitudinal Study team at the Office for National Statistics for making available the LS data and the Social Statistics Research Unit team at City University for extraction of data Stephen Sharp of the London School of Hygiene and Tropical Medicine gave advice on some statistical issues.

The views expressed in this paper are not necessarily those of the Office for National Statistics or the Department of Health.

1 Fox A, Goldblatt PO. Socio-demographic differentials. Longitudinal Study 1971-1975. LS No 1 chapter 5. London: HMSO, 1982.

2 Goldblatt P. Mortality and alternative social classifications. In: Longitudinal Study: mortality and social organisation. LS No 6. London: HMSO, 1990:163-92.

3 Evans JG. Institutional care and elderly people. BMF 1993; 306:806-7.

4 Grundy E, Glaser K. Trends in, and transitions to institutional residence among older people in England and institutional residence among older people in England and 531-40.

5 Goldblatt P. Mortality by social class, 1971-1985. Popul Trends 1989;56:6-15.

6 Blane D, Harding S, Rosato M. Does social mobility affect the size of the socioeconomic mortality differential? evidence from the Office for national Statistics Longitudinal Study. Fournal of the Royal Satistical Society Series $A$ 1999;162:59-70.

7 Smith J, Harding S. Mortality of women and men using alternative social classifications. In: Drever F, Whitehead M, eds. Health inequalities. London: The Stationery Office (Series DS NO 15), 1997.

8 Grundy E. Ageing: age-related change in later life. In: Murphy M, Hobcraft J, eds. Population Research in Britain. London: LSE Population Investigation Committee, 13356.

9 OPCS Longitudinal Study. User manual. London: City University, 1990.

10 Census 1981. Definitions. CEN81DEF. London: HMSO, 1981:10.

11 Dale A, Marsh C, eds. The 1991 census user's guide. London: HMSO: 1993:23.

12 Statacorp Stata. Statistical software release 4.0. Volume 2. College Station, TX: Stata Corporation, 1995:506-13.

13 Filakti H, Fox J. Differences in mortality by housing tenure and by car access from the OPCS Longitudinal Study. Popul Trends 1995;81:27-30.

14 Harding S. Social class differences in mortality of men: recent evidence from the OPCS Longitudinal Study. Popu Trends 1995;80:31-7.

15 Arber S, Ginn J. Gender and inequalities in health in later life. Soc Sci Med 1993;36:33-46.
16 Marmot M, Shipley M. Do socioeconomic differences in mortality persist after retirement? 25 year follow-up of civil mortality persist after retirement? 25 year follow-up of civil
servants from the first Whitehall Study. BMF 1996;313: servants $1177-80$

17 Vicente L, Wiley JA, Carrington RA. The risk of institutionalization before death. Gerontologist 1979;19:361-7.

18 Branch LG, Jette AM. A prospective study of long-term care institutionalization among the aged. Am f Public Health 1982;72:1373-9

19 Grundy E. Socio-Demographic variations in rates of movement into institutions among elderly people in England and Wales: An analysis of linked census and mortality data 1971-1985. Population Studies 1992;46:65-84.

20 Woo J, Ho SC, Lau J, et al. Age and marital status are major factors associated with institutionalisation in elderly Hong Kong Chinese. I Epidemiol Community Health 1994;48: 306-9.

21 Palmore E. Total chance of institutionalization among the aged. Gerontologist 1976;16:504-7.

22 Greenberg J, Ginn A. A multivariate analysis of the predictors of long-term care placement. Home Health Care Services Ouarterly 1979;1:75-99.

23 Fox A, Goldblatt PO, Adelstein AM. Selection and mortality differentials. F Epidemiol Community Health 1982; 36:69-79.

24 Arber S, Ginn J. Gender and later life. London: Sage, 1991:159-64, 170-2.

25 Davis MA, Neuhaus JM, Moritz DJ, et al. Living arrangements and survival among middle-aged and older adults in the NHANES 1 Epidemiologic Follow-up Study. Am F Public Health 1992;82:401-6

26 Goldman N, Korenmen S, Weinstein R. Marital status and health among the elderly. Soc Sci Med 1995;40:1717-30.

27 Ljungquist B, Sundstrỏm G. Health and social networks as predictors of survival in old age. Scand F Soc Med 1996;24: $90-101$.

28 Fox J, Goldblatt P, Jones D. Social class mortality differentials: artefact, selection or life circumstances? $\mathcal{F}$ Epidemiol Community Health 1985;39:1-8.

29 Murray Parkes C, Benjamin B, Fitzgerald RG. Broken heart: a statistical study of increased mortality among widheart: a statistical study of

30 Martikainen P, Valkonen T. Mortality after death of spouse in relation to duration of bereavement in Finland. $f$ Epidemiol Community Health 1996;50:264-8.

31 Rogers RA. Sociodemographic characteristics of long-lived and healthy individuals. Population Development Review 1995;21:33-58.

32 Kaplan GA, Seeman TE, Cohen RD, et al. Mortality among the elderly in the Alameda County Study: behavioural and demographic risk factors. Am f Public Health 1987;77:30712. [Erratum 1987;77:818.]

33 Davis M, Neuhaus JM, Moritz DJ, et al. Health behaviors and survival among middle-aged and older men and women in NHANES 1 epidemiologic follow-up study. Prev Med 1994;23:369-76.

34 Davey Smith G, Shipley MJ, Rose G. Magnitude and causes of socioeconomic differentials in mortality: further evidence from the Whitehall Study. $\mathcal{F}$ Epidemiol Community Health 1990;44:265-70.

35 Cairney J, Arnold R. Social class, health and aging: socioeconomic determinants of self-reported morbidity among non-institutionalised elderly in Canada. Can F Public Health 1996;87:199-203.

36 Impallomeni $M$, Starr J. The changing face of community and institutional care for the elderly. $f$ Public Health Med 1995;17:171-8

37 Stern MC, Jagger C, Clarke M, et al. Residential care for elderly people: a decade of change. BMF 1993;306:827-30. 